\title{
Evaluation of the anti-inflammatory actions of various functional food materials including glucosamine on synovial cells
}

\author{
YOSHIE YAMAGISHI ${ }^{1,2}$, AKIMASA SOMEYA ${ }^{1}$, KENSUKE IMAI $^{3}$, JUNJI NAGAO $^{3}$ and ISAO NAGAOKA ${ }^{1}$ \\ ${ }^{1}$ Department of Host Defense and Biochemical Research, Juntendo University, \\ Graduate School of Medicine, Bunkyo-ku, Tokyo 113-8421; ${ }^{2}$ Protein Chemical Co., Ltd., \\ Chiyoda-ku, Tokyo 100-0011; ${ }^{3}$ KOBAYASHI Pharmaceutical Co., Ltd., Ibaraki, Osaka 567-0057, Japan
}

Received August 5, 2016; Accepted February 27, 2017

DOI: $10.3892 / \mathrm{mmr} .2017 .6691$

\begin{abstract}
The anti-inflammatory actions of glucosamine $(\mathrm{GlcN})$ on arthritic disorders involve the suppression of inflammatory mediator production from synovial cells. GlcN has also been reported to inhibit the activation of the p38 mitogen-activated protein kinase (MAPK) pathway. The present study aimed to determine the cooperative and anti-inflammatory actions of functional food materials and evaluated the production of interleukin (IL)-8 and phosphorylation of p38 MAPK in IL-1 $\beta$-activated synovial cells, incubated with the combination of $\mathrm{GlcN}$ and various functional food materials containing L-methionine (Met), undenatured type II collagen (UC-II), chondroitin sulfate (CS), methylsulfonylmethane (MSM) and agaro-oligosaccharide (AO). The results indicated that Met, UC-II, CS, MSM and AO slightly or moderately suppressed the IL- $1 \beta$-stimulated IL- 8 production by human synovial MH7A cells. The same compounds further decreased the IL-8 level lowered by GlcN. Similarly, they slightly suppressed the phosphorylation level of p38 MAPK and further reduced the phosphorylation level lowered by GlcN. These observations suggest a possibility that these functional food materials exert an anti-inflammatory action (inhibition of IL-8 production) in combination with GlcN by cooperatively suppressing the $\mathrm{p} 38$ MAPK signaling (phosphorylation).
\end{abstract}

\section{Introduction}

Glucosamine (GlcN), a naturally occurring amino monosaccharide, is present in the connective and cartilage tissues and contributes to maintaining their strength, flexibility and elasticity. GlcN has been widely used as a supplement for

Correspondence to: Professor Isao Nagaoka, Department of Host Defense and Biochemical Research, Juntendo University, Graduate School of Medicine, 2-1-1 Hongo, Bunkyo-ku, Tokyo 113-8421, Japan

E-mail: nagaokai@juntendo.ac.jp

Key words: glucosamine, functional food material, cooperative action, anti-inflammatory action, synovial cell alleviating the symptoms of osteoarthritis (OA). According to previous biochemical and pharmacological findings, the administration of GlcN normalized cartilage metabolism by inhibiting degradation (1) and stimulating the synthesis of proteoglycans $(2,3)$, and restores articular functions. GlcN has also been reported to exert an anti-inflammatory action by inhibiting the production of inflammatory mediators and inflammatory cytokines, including nitric oxide (NO), prostaglandin (PG) $\mathrm{E}_{2}$ and interleukin (IL)-8 via the suppression of the activation of the p38 mitogen activated protein kinase (MAPK) signaling pathway and nuclear factor (NF) $-\kappa \mathrm{B}$ signaling (4-9).

Furthermore, other functional food materials are understood to exhibit anti-inflammatory actions. Chondroitin sulfate (CS) inhibits the activation and nuclear translocation of $\mathrm{NF}-\kappa \mathrm{B}$ in chondrocytes and synoviocytes (10). Methylsulfonylmethane (MSM) and agaro-oligosaccharide (AO) are reported to inhibit lipopolysaccharide (LPS)-induced production of NO in the RAW264.7 mouse macrophage-like cell line $(11,12)$. In addition, AO, CS and MSM reduce the symptoms of rheumatoid arthritis models (12-14). Similarly, L-methionine (Met) reduces the symptoms of rheumatoid arthritis in model animals (15), and undenatured type II collagen (UC-II) improves the symptoms of human OA (16). Thus, these functional food materials are expected to enhance the alleviation of the symptoms of OA by combination with GlcN. However, it remains to be elucidated whether the combination of these materials with GlcN cooperatively exhibits the anti-inflammatory actions.

The present study therefore aimed to determine the cooperative and anti-inflammatory actions of functional food materials, and evaluated the production of IL- 8 and phosphorylation of p38 MAPK and NF- $\kappa B$ in IL- $1 \beta$-activated synovial cells, incubated with the combination of GlcN and various functional food materials, containing Met, UC-II, CS, MSM, AO and other substances with anti-inflammatory or anti-arthritic action (proteoglycans, hyaluronic acid, collagen peptides, olive leaf extract, red ginger extract, Boswellia serrata extract, devil's claw and curcumin).

\section{Materials and methods}

Reagents. GlcN and Met were supplied by Protein Chemical Co., Ltd. (Tokyo, Japan), UC-II by Ryusendo Co., Ltd. (Tokyo, 
Japan), CS by Yaegaki Bio-industry, Inc. (Himeji, Japan), MSM by CIC Frontier Co., Ltd. (Tokyo, Japan) and AO by Takara Bio Inc. (Otsu, Japan). IL-1 $\beta$ was purchased from Peprotech EC Ltd. (London, UK). In addition, the effects of the following substances, which are known to exhibit anti-inflammatory or anti-arthritic action (17-25), were evaluated: Proteoglycan extracted from salmon nasal cartilage (17) was supplied by Ichimaru Pharcos Co., Ltd. (Gifu, Japan), hyaluronic acid (18) by N.C. Corporation (Kagawa, Japan), collagen peptides $(19,20)$ by Nitta Gelatin Inc. (Osaka, Japan), olive leaf extract (21) by Eisai Food \& Chemical Co., Ltd. (Tokyo, Japan), red ginger extract (22) from Oryza Oil \& Fat Chemical Co., Ltd. (Aichi, Japan), Boswellia serrata extract (23) from Nippon Shinyaku Co., Ltd., devil's claw extract (24) from Ask Intercity Co., Ltd. (Chiba, Japan) and curcumin (25) from Indena Japan Co., Ltd. (Tokyo, Japan).

Cell culture. MH7A human synovial cells (RCB1512) were purchased from RIKEN Cell Bank (Tsukuba, Japan) and were maintained in RPMI-1640 medium (Nacalai Tesque, Kyoto, Japan) supplemented with $10 \%$ fetal bovine serum (cat. no. 171012; Nichirei Biosciences Inc., Tokyo, Japan), penicillin and streptomycin at $37^{\circ} \mathrm{C}$ in $5 \% \mathrm{CO}_{2}$.

Measurement of IL-8 production. MH7A cells $\left(0.35 \times 10^{5}\right.$ cells/well $)$ were seeded and cultured into 24 -well plates overnight. The cells were then incubated with Met (50-100 $\mu \mathrm{g} / \mathrm{ml})$, UC-II $(50-100 \mu \mathrm{g} / \mathrm{ml})$, CS $(50-100 \mu \mathrm{g} / \mathrm{ml})$, MSM (2,500-5,000 $\mu \mathrm{g} / \mathrm{ml})$, AO (50-100 $\mu \mathrm{g} / \mathrm{ml})$, proteoglycan $(25-100 \mu \mathrm{g} / \mathrm{ml})$, hyaluronic acid (250-1,000 $\mu \mathrm{g} / \mathrm{ml})$, collagen peptides (100-400 $\mu \mathrm{g} / \mathrm{ml})$, olive leaf extract $(5-20 \mu \mathrm{g} / \mathrm{ml})$, red ginger extract $(10-40 \mu \mathrm{g} / \mathrm{ml})$, devil's claw extract $(25-100 \mu \mathrm{g} / \mathrm{ml})$, curcumin $(5-20 \mu \mathrm{g} / \mathrm{ml})$ and Boswellia serrata extract $(12.5 \mu \mathrm{g} / \mathrm{ml})$ or $\mathrm{GlcN}(1 \mathrm{mM})$, and a combination of GlcN and other materials for $3 \mathrm{~h}$ at $37^{\circ} \mathrm{C}$. Following this, cells were stimulated with $50 \mathrm{pg} / \mathrm{ml}$ IL-1 $\beta$ in a total volume of $0.5 \mathrm{ml}$ RPMI-1640 medium for $24 \mathrm{~h}$ at $37^{\circ} \mathrm{C}$ (4). Subsequently, IL-8 in the culture supernatants was quantified by a sandwich enzyme-linked immunosorbent assay (ELISA) using the DuoSet ELISA Development kit (R\&D Systems, Inc., Minneapolis, MN, USA). Microtiter plates (96-well half area flat bottom; Corning, Acton, MA, USA) were coated with $4 \mu \mathrm{g} / \mathrm{ml}$ mouse anti-human IL-8 antibody (cat. no. \#890805; 180-fold dilution, $25 \mu \mathrm{l} /$ well; R\&D Systems, Inc.) diluted in phosphate-buffered saline (PBS; $137 \mathrm{mM} \mathrm{NaCl}, 2.7 \mathrm{mM} \mathrm{KCl}$, $8.1 \mathrm{mM} \mathrm{Na}_{2} \mathrm{HPO}_{4}$ and $1.5 \mathrm{mM} \mathrm{KH}_{2} \mathrm{PO}_{4}$; pH7.4) overnight at $4^{\circ} \mathrm{C}$. Following washing with PBS and $0.05 \%$ Tween-20, plates were blocked with PBS containing $1 \%$ bovine serum albumin (BSA) and $0.05 \%$ sodium azide for $1 \mathrm{~h}$ at room temperature. The plates were subsequently washed three times with PBS containing $0.05 \%$ Tween-20, $25 \mu \mathrm{l} /$ well culture supernatants or standards (15-2,000 pg/ml) were added, and plates were incubated for $2 \mathrm{~h}$ at room temperature. Following washing three times with PBS containing $0.05 \%$ Tween-20, the plates were incubated with $3.6 \mu \mathrm{g} / \mathrm{ml}$ of biotinylated goat anti-human IL-8 antibody (180-fold dilution; cat. no. \#890805, R\&D Systems, Inc.) for $2 \mathrm{~h}$ at room temperature, then washed and incubated with streptavidin-horseradish peroxidase (cat. no. \#890803; 200-fold dilution, $25 \mu \mathrm{l} /$ well; R\&D Systems, Inc.) at room temperature for $10 \mathrm{~min}$. The plates were washed again and incubated with $25 \mu$ l tetramethyl benzidine liquid substrate. The reaction was terminated with $1 \mathrm{M} \mathrm{H}_{2} \mathrm{SO}_{4}$, and the plates were read immediately at a wavelength of $450 \mathrm{~nm}$ with a microplate reader (Model 680; Bio-Rad, Hercules, CA, USA). The detection limit was $<15 \mathrm{pg} / \mathrm{ml}$.

Phosphorylation of p38MAPK and NF- $\kappa$ B. MH7A cells (9x10 $/$ well) were seeded and cultured in $35 \mathrm{~mm}$ tissue culture dishes overnight. Thereafter, the cells were incubated with $1 \mathrm{mM} \mathrm{GlcN}, 100 \mu \mathrm{g} / \mathrm{ml} \mathrm{Met,} 50 \mu \mathrm{g} / \mathrm{ml} \mathrm{UC}-\mathrm{II}, 50 \mu \mathrm{g} / \mathrm{ml} \mathrm{CS}$ or 2,500 $\mu \mathrm{g} / \mathrm{ml} \mathrm{MSM,} 100 \mu \mathrm{g} / \mathrm{ml} \mathrm{AO}$ and a combination of $\mathrm{GlcN}$ and other materials for $3 \mathrm{~h}$, and stimulated with $200 \mathrm{pg} / \mathrm{ml}$ $\mathrm{IL}-1 \beta$ for $10 \mathrm{~min}$ at $37^{\circ} \mathrm{C}(8,9)$. Following washing with ice-cold PBS containing $100 \mathrm{mM} \mathrm{Na} \mathrm{VO}_{4}$, the cells were harvested in $1.2 \mathrm{ml}$ lysis buffer (1\% Triton X-100, 0.5\% Nonidet P-40, $10 \mathrm{mM}$ Tris- $\mathrm{HCl}$ and $150 \mathrm{mM} \mathrm{NaCl}$; $\mathrm{pH} 7.4$ ) containing 1/25 v/v Complete $^{\mathrm{TM}}$ (Roche Diagnostics GmbH, Mannheim, Germany) and 1/100 v/v Phosphatase Inhibitor Cocktail ${ }^{\mathrm{TM}}$ (Nacalai Tesque, Kyoto, Japan). Following sonication, the lysates were centrifuged at $4^{\circ} \mathrm{C}$ at $12,000 \mathrm{x} \mathrm{g}$ for $10 \mathrm{~min}$ and the supernatants were recovered. The protein concentrations of the supernatants were determined with a Bicinchoninic Acid protein assay kit (Pierce; Thermo Fisher Scientific, Inc., Waltham, MA, USA) using BSA as a standard. The supernatants were mixed with 6X SDS-PAGE sample buffer and boiled for $3 \mathrm{~min}$. Samples (10 $\mu \mathrm{g}$ protein/lane) were separated by $12 \%$ SDS-PAGE and electrophoretically transferred onto an Immobilon-P polyvinylidene difluoride membrane (EMD Millipore, Billerica, MA, USA). To detect phosphorylated p38 MAPK and NF- $\mathrm{B}$ levels, the membranes were blocked in Blocking One solution (Nacalai Tesque, Inc., Kyoto, Japan), and probed with a mouse anti-phosphorylated (p)-p38 MAPK monoclonal antibody (pT180/pY182; 1,000-fold dilution; cat. no.\#612168; BD Bioscience Pharmingen, San Diego, CA, USA) or a rabbit anti-phosphorylated NF- $\mathrm{B}$ p 65 monoclonal antibody (Ser 536; 250-fold dilution; cat. no. \#3033; Cell Signaling Technology, Inc., Danvers, MA, USA). Horseradish peroxidase (HRP)-conjugated goat anti-mouse immunoglobulin (Ig)G/IgM (5,000-fold dilution; cat. no. \#115-035-044; Jackson ImmunoResearch Laboratories, Inc., West Grove, PA, USA) or HRP-conjugated goat anti-rabbit IgG (5,000-fold dilution; cat. no. \#115-035-144; Jackson ImmunoResearch Laboratories, Inc.) served as secondary antibodies.

The membranes were stripped by incubating in Restore Western Stripping Buffer (Pierce; Thermo Fisher Scientific, Inc.) at $37^{\circ} \mathrm{C}$ for $15 \mathrm{~min}$. The p38 MAPK and $\mathrm{NF}-\kappa \mathrm{B}$ proteins contained in each sample were detected by reprobing with mouse anti-p38MAPK (2,000-fold dilution; SAPK2a; cat. no. \#612168; BD Bioscience Pharmingen) or rabbit anti-NF-кB (2,000-fold dilution; D14E12; cat. no. \#8242; Cell Signaling Technology, Inc.) primary antibodies followed by the HRP-conjugated goat anti-mouse (5,000-fold dilution) or anti-rabbit (5,000-fold dilution) $\operatorname{IgG}$ secondary antibodies. Signals were detected with SuperSignal West Pico Chemiluminescent Substrate (Pierce; Thermo Fisher Scientific, Inc.), and quantified using a LAS-3000 luminescent image analyzer and Multi Gauge version 3.0 (both from Fujifilm Corporation, Tokyo).

Statistical analysis. Data are expressed as the mean \pm standard deviation, and were analyzed using one-way analysis of 

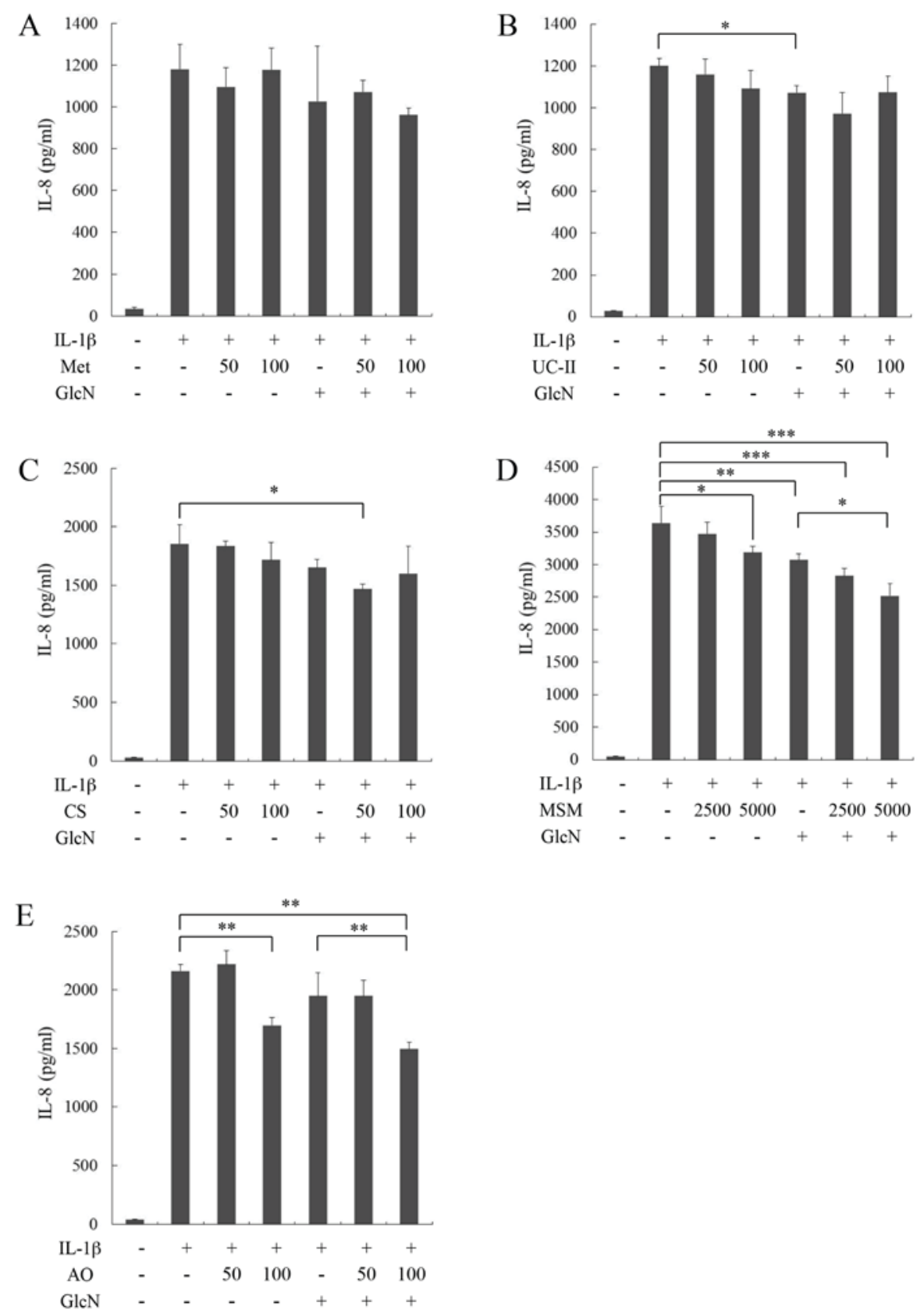

Figure 1. Effect of functional food materials and glucosamine $(\mathrm{GlcN})$ on IL-1 $\beta$-stimulated IL-8 production by MH7A cells. MH7A cells were incubated in the absence (-) or presence (+) of (A) Met (B) UC-II, (C) CS, (D) MSM and (E) AO, in with or without or GlcN and IL-1 $\beta$. Data are presented as the mean \pm standard deviation of three separate experiments. The level of IL-1 $\beta$-stimulated IL-8 production was compared between cells with and without functional food materials or glucosamine, and between cells treated with glucosamine alone and those treated with a combination of functional food materials and glucosamine. "P<0.05, ${ }^{* *} \mathrm{P}<0.01$ and ${ }^{* * *} \mathrm{P}<0.001$. IL, interleukin. Met, methionine; UC-II, undenatured type II collagen; CS, chondroitin sulfate; MSM, methysulfonylmethane; AO, agaro-oligosaccharide; GlcN, glucosamine; IL-1 $\beta$, interleukin-1 $\beta$.

variance followed by a post hoc Bonferroni test for multiple comparisons. Statistical analysis was performed using GraphPad Prism software version 5 (GraphPad Software, Inc., La Jolla, CA, USA). P $<0.05$ was considered to indicate a statistically significant difference.

\section{Results}

Effects of Met, UC-II, CS, MSM, AO and GlcN on $I L-1 \beta$-stimulated IL-8 production by MH7A cells. To evaluate the effects of functional food materials and GlcN on IL-8 production, MH7A was stimulated with IL-1 $\beta$ in the presence of Met, UC-II, CS, MSM, AO or GlcN, and the combination of GlcN and other materials. Met (50 and $100 \mu \mathrm{g} / \mathrm{ml}$ ), UC-II (50 and $100 \mu \mathrm{g} / \mathrm{ml})$, CS $(50$ and $100 \mu \mathrm{g} / \mathrm{ml}), \operatorname{MSM}(2,500$ and $5,000 \mu \mathrm{g} / \mathrm{ml})$ and $\mathrm{AO}(50$ and $100 \mu \mathrm{g} / \mathrm{ml})$ slightly or moderately suppressed the IL- $1 \beta$-stimulated IL- 8 production by MH7A cells (Fig. 1A-E, respectively), although GlcN (1 mM) suppressed IL-8 production more potently compared with other materials (Fig. 1). The combination of GlcN and these functional food materials on IL-8 production was evaluated. Met $(100 \mu \mathrm{g} / \mathrm{ml})$, UC-II $(50 \mu \mathrm{g} / \mathrm{ml})$, CS $(50 \mu \mathrm{g} / \mathrm{ml}), \operatorname{MSM}(2,500$ and $5,000 \mu \mathrm{g} / \mathrm{ml}, \mathrm{P}<0.05)$ and AO $(100 \mu \mathrm{g} / \mathrm{ml}, \mathrm{P}<0.01)$ further decreased the IL-8 level lowered 
A

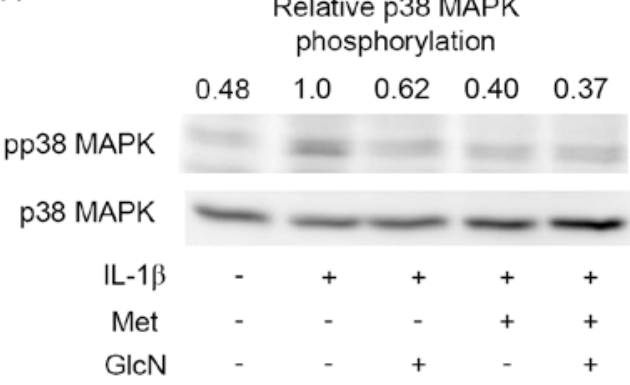

C

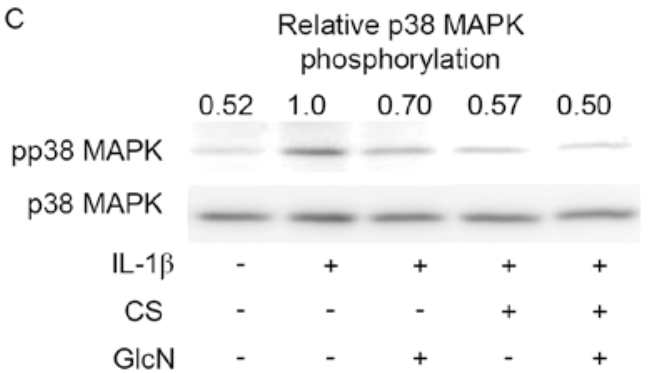

$E$

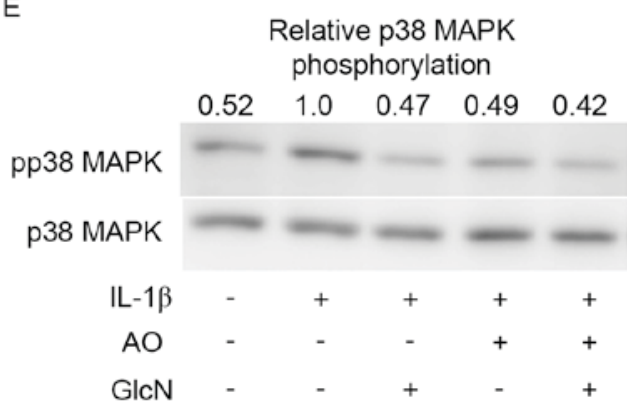

B

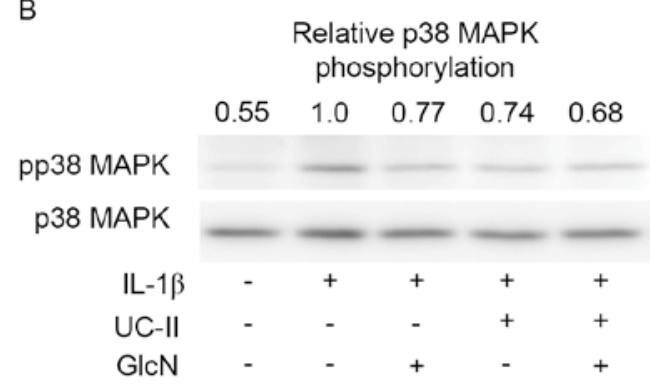

D

Relative p38 MAPK

phosphorylation

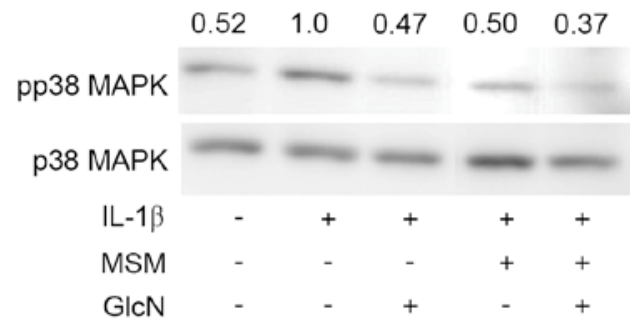

Figure 2. Effect of functional food materials and glucosamine on the phosphorylation of p38 MAPK. Representative western blot images of MH7A cells incubated in the absence (-) or presence (+) of (A) Met, (B) UC-II, (C) CS, (D) MSM, (E) AO, with or without or GlcN and IL-1 $\beta$. Images and quantified data are representative of three separate experiments. MAPK, mitogen-activated protein kinase; Met, methionine; UC-II, undenatured type II collagen; CS, chondroitin sulfate; MSM, methysulfonylmethane; AO, agaro-oligosaccharide; GlcN, glucosamine; IL-1 $\beta$, interleukin-1 $\beta$; pp38, phosphorylated p38.

by GlcN (Fig. 1A-E, respectively). In contrast, proteoglycan (25-100 $\mu \mathrm{g} / \mathrm{ml})$, hyaluronic acid $(250-1,000 \mu \mathrm{g} / \mathrm{ml})$, collagen peptides $(100-400 \mu \mathrm{g} / \mathrm{ml})$, olive leaf extract $(5-20 \mu \mathrm{g} / \mathrm{ml})$, red ginger extract $(10-40 \mu \mathrm{g} / \mathrm{ml})$, devil's claw extract $(25-100 \mu \mathrm{g} / \mathrm{ml})$, curcumin $(5-20 \mu \mathrm{g} / \mathrm{ml})$ and Boswellia serrata extract $(12.5 \mu \mathrm{g} / \mathrm{ml})$ neither suppressed the IL-1 $\beta$-stimulated IL-8 production by MH7A cells nor affected the GlcN-induced suppression of IL-8 production (data not shown).

Effects of Met, UC-II, CS, MSM, AO and GlcN on phosphorylation of $38 M A P K$ and $N F-\kappa B$. To determine whether the suppressive action of Met, UC-II, CS, MSM, AO or GlcN, and the combination of $\mathrm{GlcN}$ and other materials on the synovial cell activation is mediated by the actions of p38 MAPK and $\mathrm{NF}-\kappa \mathrm{B}$ signaling, the effects of these substances on the phosphorylation of p38 MAPK and NF- $\mathrm{BB}$ p65 was investigated. Met $(100 \mu \mathrm{g} / \mathrm{ml})$, UC-II $(50 \mu \mathrm{g} / \mathrm{ml})$, CS $(50 \mu \mathrm{g} / \mathrm{ml}), \mathrm{MSM}$ $(2,500 \mu \mathrm{g} / \mathrm{ml})$ and AO $(100 \mu \mathrm{g} / \mathrm{ml})$ slightly or moderately suppressed the IL-1 $\beta$-stimulated phosphorylation of $\mathrm{p} 38$ MAPK (Fig. 2A-E, respectively), although GlcN (1 mM) substantially suppressed the IL-1 $\beta$-induced phosphorylation of p38 MAPK (Fig. 2). Notably, Met, UC-II, CS, MSM and AO slightly or moderately decreased the phosphorylation level of p38 MAPK lowered by GlcN. In addition, Met further reduced the phosphorylation level of NF- $\mathrm{B}$ p65 lowered by GlcN (Fig. 3), although the suppressive effects of UC-II, CS, MSM and $\mathrm{AO}$ on the phosphorylation of $\mathrm{NF}-\kappa \mathrm{B}$ p 65 were not clearly observed (data not shown). However, the suppressive effects of Met, UC-II, CS, MSM, AO and GlcN on the phosphorylation levels of p38 MAPK and NF- $\mathrm{B}$ p65 were not statistically significant (data not shown).

\section{Discussion}

The anti-inflammatory actions of GlcN in arthritic disorders involve the suppression of inflammatory mediator production from synovial cells and chondrocytes (4-6). In addition, GlcN has been reported to inhibit activation of the p38 MAPK $\mathrm{NF}-\kappa \mathrm{B}$ signaling pathways (4,6-9). The present study examined the anti-inflammatory actions of other functional food materials; the effects of Met, UC-II, CS, MSM and AO were evaluated using the MH7A human synovial cell line, and IL-8 as an inflammatory cytokine/chemokine. The results indicated that Met, UC-II, CS, MSM and AO slightly or moderately 


\section{Relative NF- $\kappa$ B phosphorylation}

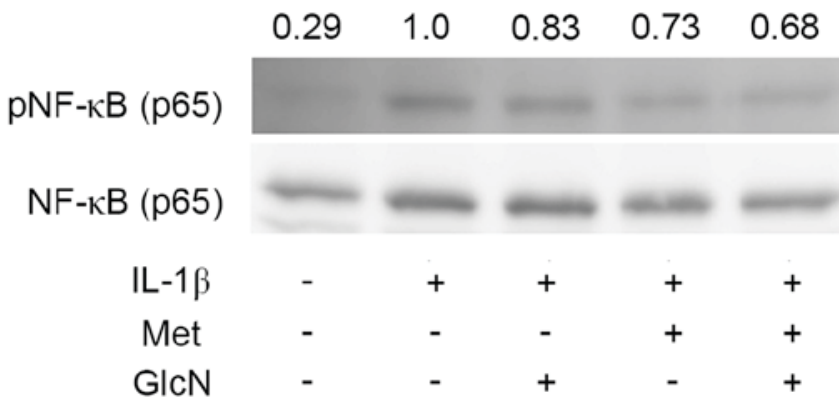

Figure 3. Effect of Met and GlcN on phosphorylation of NF- $\mathrm{B}$ p65 Representative western blot images of MH7A cells incubated in the absence (-) or presence (+) of Met, with or without GlcN and IL-1 $\beta$. Images and quantified data are the representative of three separate experiments. NF- $\kappa \mathrm{B}$, nuclear factor- $\kappa \mathrm{B}$; Met, methionine; GlcN, glucosamine; IL-1 $\beta$, interleukin-1 $\beta$; $p$, phosphorylated.

suppressed IL-1 $\beta$-stimulated IL- 8 production by MH7A cells. Notably, Met, UC-II, CS, MSM and AO further decreased the IL-8 levels lowered by GlcN. Similarly, Met, UC-II, CS, MSM and AO slightly or moderately suppressed the phosphorylation levels of p38 MAPK and further reduced the phosphorylation level lowered by GlcN (statistical data not shown). These observations suggested a possibility that these functional food materials exerted an anti-inflammatory action (inhibition of IL-8 production) in combination with $\mathrm{GlcN}$ by cooperatively suppressing p38 MAPK signaling (phosphorylation).

The functional food materials evaluated in the present study are included in various foods (http://www.naturaldatabase.com/): GlcN is contained in the shells of crustaceans, including shrimps and crabs; Met is contained mainly in meat, vegetables and nuts; UC-II and CS are contained in cartilage; MSM is present in milk, tea and vegetables; and, $\mathrm{AO}$ is contained in agar. GlcN has been reported to suppress the progression of adjuvant arthritis by inhibiting synovial hyperplasia, cartilage destruction, inflammatory cell infiltration and the production of inflammatory mediators (NO and $\mathrm{PGE}_{2}$ ) (26). Furthermore, GlcN suppressed the progression of an experimental OA model by inhibiting type II collagen degradation and enhancing type II collagen synthesis (27). Among the functional food materials, Met is reported to suppress the progression of adjuvant arthritis by inhibiting the synovial hyperplasia and production of inflammatory mediators ( $\mathrm{NO}$ and $\mathrm{PGE}_{2}$ ) (15). CS exerts an anti-inflammatory action by reducing $\mathrm{NF}-\kappa \mathrm{B}$ nuclear translocation in synoviocytes and chondrocytes (10). AO suppresses the elevated levels of $\mathrm{NO}, \mathrm{PGE}_{2}$, and pro-inflammatory cytokines including tumor necrosis factor (TNF)- $\alpha$, IL-1 $\beta$ and IL- 6 by inducing heme oxygenase-1 in LPS-stimulated monocytes and macrophages (28). MSM inhibits the LPS-induced release

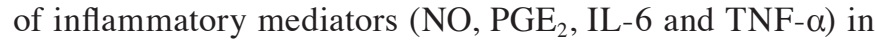
murine macrophages through the downregulation of $\mathrm{NF}-\kappa \mathrm{B}$ signaling (11). UC-II suppresses collagen-induced arthritis by inducing $\mathrm{CD}^{+}{ }^{+} \mathrm{CD} 25^{+}$regulatory T cells (29). Met reduces the symptoms of rheumatoid arthritis in model animals (15). AO, CS and MSM reduce the symptoms of rheumatoid arthritis models (12-14). UC-II improves the symptoms of human OA (16). The present study revealed that these functional food materials slightly inhibit the activation of synovial cells by suppressing IL-8 production and p38 MAPK signaling by themselves. Furthermore, the combinations of these functional food materials and GlcN cooperatively inhibit the synovial cell activation (IL-8 production) and p38 MAPK signaling. Therefore, the combinations of these materials and GlcN are expected to exhibit the chondroprotective action on cartilage-degenerative diseases including OA and rheumatoid arthritis by suppressing p38 MAPK signaling.

IL-1 $\beta$ activates a variety of signaling cascades (including p38MAPK and NF- $\kappa$ B pathways), which lead to the induction of inflammatory response (i.e., the production of inflammatory cytokines and mediators) $(30,31)$. The present study demonstrated that $\mathrm{GlcN}$ and other functional food materials (mentioned above) cooperatively suppress the IL- $1 \beta$-induced IL-8 production and the phosphorylation of p38MAPK (Figs. 2 and 3) (data not shown). These observations suggest that GlcN and other functional food materials inhibit the IL-1 $\beta$-induced synovial cell activation (i.e., IL-8 production) possibly via the suppression of intracellular signaling including p38MAPK.

It is now recognized that the addition of $O$-linked $\mathrm{N}$-acetylGlcN ( $O$-GlcNAc) to target proteins may modulate cellular functions, including nuclear transport, transcription, translation, cell signaling, apoptosis and cell shape $(32,33)$. We previously suggested (8) that GlcN suppressed the TNF- $\alpha$-induced intercellular adhesion molecule (ICAM-1) and monocyte chemoattractant protein-1 (MCP-1) expression in endothelial cells, possibly by downregulating the phosphorylation of p38 MAPK and NF- $\kappa \mathrm{B}$ via $O-$ GlcNAc modification, using an $O$-GlcNAc transferase (OGT) inhibitor, alloxan. Thus, it is reasonable to hypothesize that GlcN inhibits the IL-1 $\beta$-induced synovial cell activation (i.e., IL-8 production), possibly by downregulating the phosphorylation of p38 MAPK and NF- $\kappa$ B via $O-$ GlcNAc modification. However, it remains unclear whether $O$-GlcNAc modification is involved in the suppression of p38 MAPK and NF- $\kappa \mathrm{B}$ phosphorylation by other functional food materials evaluated in this study.

By contrast, proteoglycan, hyaluronic acid, collagen peptides, olive leaf extract, red ginger extract, Boswellia serrata extract, devil's claw extract and curcumin did not suppress the IL-1 $\beta$-stimulated IL- 8 production by MH7A cells under the experimental conditions of the present study (data not shown). Proteoglycan is reported to attenuate the progression of collagen-induced arthritis by modulating immune response of splenocytes to collagen stimulation (17). Hyaluronic acid exerts the anti-inflammatory action by inhibiting bradykinin-induced arachidonic acid release from synovial fibroblasts in osteoarthritic inflamed joints (18). Collagen peptides exert a chondroprotective action on OA by inhibiting matrix metalloproteinase-13 expression and type II collagen degeneration (19). Olive leaf extract exhibits the anti-arthritis effect by preventing the destruction of cartilage and limiting peri-articular soft tissue inflammation in kaolin- and carrageenan-induced arthritis (21). An active substance of red ginger extract, 6-Gingerol, exerts its anti-inflammatory action by reducing the inducible nitric oxide synthase and $\mathrm{TNF}-\alpha$ expression through the blocking of $\mathrm{NF}-\mathrm{\kappa B}$ and protein kinase $\mathrm{c}$ signaling in LPS-stimulated macrophages (22). Boswellia serrata 
exhibits an anti-inflammatory action on colonic epithelial cells by suppressing cytokine- and hydrogen peroxide-induced activation of NF- $\mathrm{KB}$ (23). Harpagophytum procumbens (devil's claw) suppresses the inflammatory reaction of LPS-stimulated human monocytes by inhibiting the release of cytokines and $\mathrm{PGE}_{2}$, and the expression of COX-2, IL- 6 and TNF- $\alpha$ mRNA, without affecting the NF- $\kappa \mathrm{B}$ and MAPK signaling pathways (24). Curcumin reduces LPS-stimulated inflammatory responses ( $\mathrm{NO}, \mathrm{PGE}_{2}$ and cytokine production) in the lungs of diabetic rats by suppressing NF- $\kappa \mathrm{B}$ activation (25). Thus, all the functional food materials described above are unlikely to exhibit anti-inflammatory actions on IL-1 $\beta$-induced production of IL- 8 by synovial cells evaluated in the present study, although they suppress the inflammatory reactions assessed under other experimental conditions.

In conclusion, the present study demonstrated that a combination of functional food materials (Met, UC-II, CS, MSM and AO) and GlcN resulted in a chondroprotective action on cartilage-degenerative diseases. However, it is for future studies to elucidate whether the combinations of these functional food materials and GlcN exerts a therapeutic action in vivo, using animal models of $\mathrm{OA}$ and rheumatoid arthritis.

\section{Acknowledgements}

The present study was supported in part by a grant from the Strategic Research Foundation Grant-aided Project for Private Universities from the Ministry of Education, Culture, Sport, Science and Technology (Tokyo, Japan; 2014 to 2018; grant no. S1411007). The authors would like to thank Dr. K Miyazawa (Kissei Pharmaceutical Co., Ltd., Nagano, Japan) for the establishment of MH7A cells, and the researchers of Department of Host Defense and Biochemical Research, Juntendo University, Graduate School of Medicine, for technical assistance and helpful discussions.

\section{References}

1. Fenton JI, Chlebec-Brown KA, Peters TL, Caron JP and Orth MW: Glucosamine $\mathrm{HCl}$ reduces equine articular cartilage degradation in explants culture. Osteoarthritis Cartilage 8: 258-265, 2000.

2. Oegema TR Jr, Deloria LB, Sandy JD and Hart DA: Effect of oral glucosamine on cartilage and meniscus in normal and chymopapain-injected knees of young rabbits. Arthritis Rheum 46: 2495-2503, 2002.

3. Gouze JN, Bordji K, Gulberti S, Terlain B, Netter P, Magdalou J, Fournel-Giqleux S and Ouzzine M: Interleukin-1beta down-regulates the expression of glucuronosyltransferase I, a key enzyme priming glycosaminoglycan biosynthesis: Influence of glucosamine on Interleukin-1beta-mediated effects in rat chondrocytes. Arthritis Rheum 44: 351-360, 2001.

4. Hua J, Sakamoto K, Kikukawa T, Abe C, Kurosawa H and Nagaoka I: Evaluation of the suppressive actions of glucosamine on the interleukin-1beta-mediated activation of synoviocytes. Inflamm Res 56: 432-438, 2007.

5. Nagaoka I: Recent aspects of the chondroprotective and anti-inflammatory actions of glucosamine, a functional food. Juntendo Medical J 60: 580-587, 2014.

6. Largo R, Alvarez-Soria MA, Díez-Ortego I, Sánchez-Pernatute O, Eqido $J$ and Herrero-Beaumont G: Glucosamine inhibits IL-1beta-induced NFkappaB activation in human osteoarthritic chondrocyte. Osteoarthritis Cartilage 11: 290-298, 2003.

7. Rafi MM, Yadav PN and Rossi AO: Glucosamine inhibits LPS-induced COX-2 and iNOS expression in mouse macrophage cells (RAW 264.7) by inhibition of p38-MAP kinase and transcription factor NF-kappaB. Mol Nutr Food Res 51: 587-593, 2007.
8. Ju Y, Hua J, Sakamoto K, Ogawa H and Nagaoka I: Modulaion of TNF- $\alpha$-induced endothelial cell activation by glucosamine, a naturally occurring amino monosaccharide. Int J Mol Med 22: 809-815, 2008.

9. Yomogida S, Hua J, Sakamoto K and Nagaoka I: Glucosamine suppresses interleukin-8 production and ICAM-1expression by TNF- $\alpha$-stimulated human colonic epithelial HT-29 cells. Int J Mol Med 22: 205-211, 2008.

10. Iouv M, Dumais G and du Souich P: Anti-inflammatory activity of chondroitin sulfate. Osteoarthritis Cartilage 16 (Suppl 3): S14-S18, 2008

11. Kim YH, Kim DH, Lim H, Baek DY, Shin HK and Kim JK: The anti-inflammatory effects of methylsulfonylmethane on lipopolysaccharide-induced inflammatory responses in murine macrophages. Biol Pharm Bull 32: 651-656, 2009.

12. Ohnogi H, Kudo Y, Hayami S, Mizutani S and Enoki T: Synergistic anti-inflammatory effects of agaro-oligosaccharides and glucosamine in vivo and in vitro. Glucosamine Res 8: 51-56, 2012 (In Japanese).

13. Volpi N: Anti-inflammatory activity of chondroitin sulphate: New functions from an old natural macromolecule. Inflammopharmacology 19: 299-306, 2011.

14. Hasegawa T, Ueno S and Kumamoto S: Suppressive effect of methylsulphonylmethane (MSM) on type II collagen-induced arthritis in DBA/1J mice. Jpn Pharmacol Ther 32: 421-427, 2004.

15. Yamagishi Y, Igarashi M, Suzuki A, Suguro S, Hirano SI and Nagaoka I: Evaluation of the effect of methionine and glucosamine on adjuvant arthritis in rats. Exp Ther Med 4: 640-644, 2012.

16. Lugo JP, Saiyed ZM and Lane NE: Efficacy and tolerability of an undenatured type II collagen supplement in modulating knee osteoarthritis symptoms: A multicenter randomized, double-blind, placebo-controlled study. Nutr J 15: 14, 2016.

17. Yoshimura S, Asano $K$ and Nakane A: Attenuation of collagen-induced arthritis in mice by salmon proteoglycan. Biomed Res Int 2014: 406453, 2014.

18. Tobetto K, Yasui T, Ando T, Hayashi M, Motohashi N, Shinogi M and Mori I: Inhibitort effects of hyaluronan on [14C]arachidonic acid release from labeled human synovial fibroblast. Jap J Pharmacol 60: 79-84, 1992.

19. Isaka S, Someya A, Nakamura S, Naito K, Nozawa M, Inoue N, Sugihara F, Nagaoka I and Kaneko K: Evaluation of the effect of oral administration of collagen peptides on an experimental rat osteoarthritis model. Exp Ther Med (In press).

20. Ohara H, Matsumoto H, Ito K, Iwai K and Sato K: Comparison of quantity and structures of Hydroxyproline-containing peptides in human blood after oral ingestion of gelatin hydrolysates from different sources. J Agric Food Chem 55: 1532-1535, 2007.

21. Gong D, Geng C, Jiang L, Wang L, Yoshimura H and Zhong L: Mechanisms of olive leaf extract-ameliorated rat arthritis caused by kaolin and carrageenan. Phytother Res 26: 397-402, 2012.

22. Lee TY, Lee KC, Chen SY and Chang HH: 6-Gingerol inhibits ROS and iNOS through the suppression of PKC-alpha and NF-kappaB pathways in lipopolysaccharide-stimulated mouse macrophages. Biochem Biophys Res Commun 382: 134-139, 2009.

23. Catanzaro D, Rancan S, Orso G, Dall'Acqua S, Brun P, Giron MC, Carrara M, Castagliuolo I, Ragazzi E, Caparrotta L and Montopoli M: Boswellia serrata Preserves Intestinal Epithelial Barrier from Oxidative and Inflammatory Damage. PLoS One 10: e0125375, 2015.

24. Fiebich BL, Muñoz E, Rose T, Weiss G and McGregor GP: Molecular targets of the antiinflammatory Harpagophytum procumbens (devil's claw): Inhibition of TNF $\alpha$ and COX-2 gene expression by preventing activation of AP-1. Phytother Res 26: 806-811, 2012.

25. Zhang F, Yang F, Zhao H and An Y: Curcumin alleviates lung injury in diabetic rats by inhibiting NF- $\kappa$ B pathway. Clin Exp Pharmacol Physiol 2015 (Epub ahead of print).

26. Hua J, Suguro S, Sakamoto K and Nagaoka I: Preventive actions of a high dose of glucosamine on adjuvant arthritis in rats. Inflamm Res 54: 127-132, 2005.

27. Naito K, Watari T, Furuhata A, Yomogida S, Sakamoto K, Kurosawa H, Kaneko K and Nagaoka I: Evaluation of the effect of glucosamine on an experimental rat osteoarthritis model. Life Sci 86: 538-543, 2010.

28. Enoki T, Okuda S, Kudo Y, Takshima F, Sagawa H and Kato I: Oligosaccharides from agar inhibit pro-inflammatory mediator release by inducing heme oxygenase 1 . Biosci Biotechnol Biochem 74: 766-770, 2010. 
29. Yoshinari O, Shiojima Y, Moriyama H, Shinozaki J, Nakane T, Masuda K and Bagchi M: Water-soluble undenaturated type II collagen ameliorates collagen-induced arthritis in mice. J Med Food 16: 1039-1045, 2013.

30. Parhar K, Ray A, Steinbrecher U, Nelson C and Salh B: The p38 mitogen-activated protein kinase regulates interleukin-1beta-induced IL-8 expression via an effect on the IL-8 promoter in intestinal epithelial cells. Immunology 108: 502-512, 2003.

31. Hu DN, Chen M, Zhang DY, Ye F, McCormick SA and Chan CC: Interleukin-1beta increases baseline expression and secretion of interleukin- 6 by human uveal melanocytes in vitro via the p38 MAPK/NF-kappaB pathway. Invest Ophthalmol Vis Sci 52: 3767-3774, 2011.
32. Wells L, Vosseller K and Hart GW: Glycosylation of nucleocytoplasmic proteins: Signal transduction and O-GlcNAc. Science 291: 2376-2378, 2001.

33. Hanover JA: Glycan-dependent signaling: O-linled $\mathrm{N}$-acetylglucosamine. FASEB J 15: 1865-1876, 2001. 